\title{
HIGH-RESOLUTION LIDAR DATA FOR HAINES, SOUTHCENTRAL ALASKA, DECEMBER 8-12, 2020
}

Ronald J. Daanen, Andrew M. Herbst, Katreen Wikstrom-Jones, and Gabriel J. Wolken

Raw Data File 2021-4

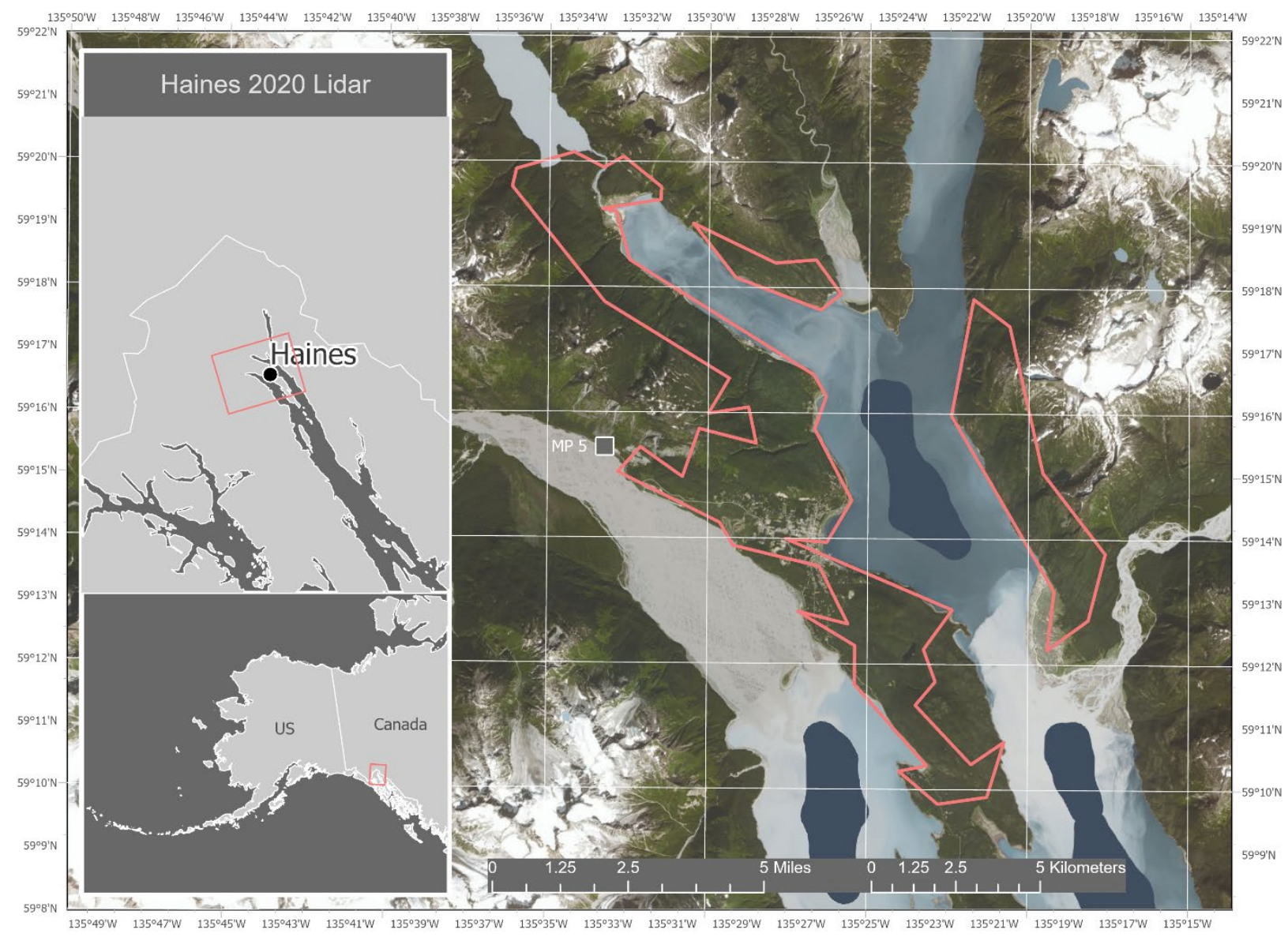

Location map of survey area with orthometric image.

This report has not been reviewed for technical content or for conformity to the editorial standards of DGGS.

2021

STATE OF ALASKA

DEPARTMENT OF NATURAL RESOURCES

DIVISION OF GEOLOGICAL \& GEOPHYSICAL SURVEYS
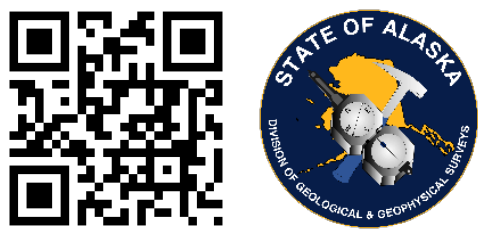


\section{STATE OF ALASKA}

Mike Dunleavy, Governor

\section{DEPARTMENT OF NATURAL RESOURCES}

Corri A. Feige, Commissioner

\section{DIVISION OF GEOLOGICAL \& GEOPHYSICAL SURVEYS}

Steve Masterman, State Geologist \& Director

Publications produced by the Division of Geological \& Geophysical Surveys are available to download from the DGGS website (dggs.alaska.gov). Publications on hard-copy or digital media can be examined or purchased in the Fairbanks office:

\section{Alaska Division of Geological \& Geophysical Surveys (DGGS)}

3354 College Road | Fairbanks, Alaska 99709-3707

Phone: 907.451.5010 | Fax 907.451.5050

dggspubs@alaska.gov |dggs.alaska.gov

\section{DGGS publications are also available at:}

Alaska State Library, Historical

Collections \& Talking Book Center

395 Whittier Street

Juneau, Alaska 99801

Alaska Resource Library and

Information Services (ARLIS)

3150 C Street, Suite 100

Anchorage, Alaska 99503

\section{Suggested citation:}

Daanen, R.P., Herbst, A.M., Wikstrom Jones, Katreen, and Wolken, G.J., 2021, High-resolution lidar data for Haines, Southcentral Alaska,

December 8-12, 2020: Alaska Division of Geological \& Geophysical

Surveys Raw Data File 2021-4, 8 p. https://doi.org/10.14509/30595
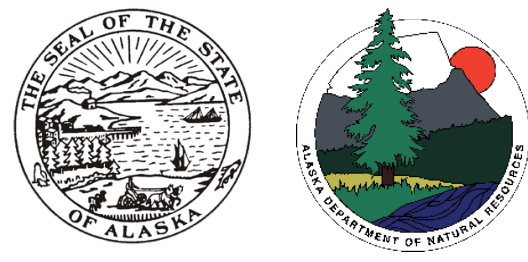


\section{HIGH-RESOLUTION LIDAR DATA FOR HAINES, SOUTHCENTRAL ALASKA, DECEMBER 8-12, 2020}

Ronald P. Daanen ${ }^{1}$, Andrew M. Herbst ${ }^{1}$, Katreen Wikstrom Jones ${ }^{1}$, and Gabriel J. Wolken ${ }^{1}$

\section{INTRODUCTION}

The Alaska Division of Geological \& Geophysical Surveys (DGGS) used aerial lidar to produce a digital terrain model (DTM), surface model (DSM), and intensity image for an area in and around the community of Haines, Alaska, as part of emergency operations in response to the December 2, 2020, landslide that claimed the lives of two residents. Airborne data were collected December 8-12, 2020, and subsequently processed in Terrasolid and ArcGIS. Ground control were collected December 15-16, by the DMLW. This data collection is released as a Raw Data File with an open end-user license. All files can be downloaded free of charge from the DGGS website: https://doi.org/10.14509/30595.

\section{LIST OF DELIVERABLES}

Classified Points

DSM and DTM

Intensity Image

Metadata

\section{MISSION PLAN}

\section{Airborne Survey Details}

DGGS operates a Riegl VUX1-LR laser scanner integrated with a GNSS and Northrop Grumman IMU system. The integration was designed by Phoenix LiDAR systems. The sensor is capable of collecting up to 820,000 points per second over a distance of $150 \mathrm{~m}$. This survey was flown with a pulse refresh rate between 200,000 and 400,000 pulses per second at a scan rate between 80 and 150 lines per second. This survey was flown with an average elevation of $400 \mathrm{~m}$ above ground level and a ground speed of approximately $40 \mathrm{~m} / \mathrm{s}$, using a Bell 206 helicopter. The scan angle was set from 55 to 305 degrees. The total area surveyed was approximately $73 \mathrm{~km}^{2}$.

\footnotetext{
${ }^{1}$ Alaska Division of Geological \& Geophysical Surveys, 3354 College Road, Fairbanks, Alaska 99709
} 


\section{Weather Conditions and Flight Times}

The airborne survey was flown December 8-12, 2020, using a Bell 206 helicopter (fig. 1). The weather throughout the survey was sub-optimal, with strong winds, light precipitation, and low-hanging clouds.

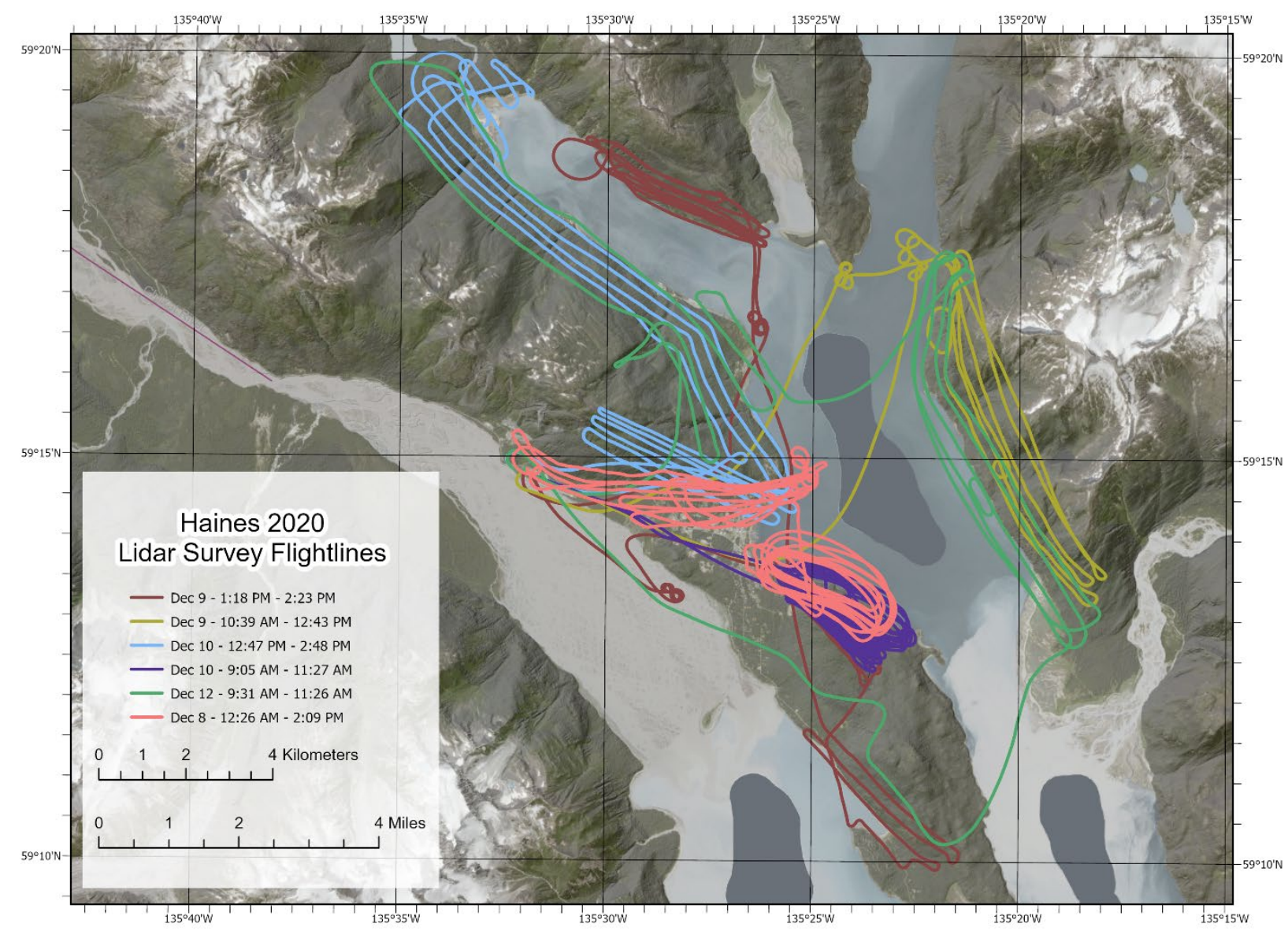

Figure 1. Project flightlines.

\section{PROCESSING REPORT}

\section{Lidar Dataset Processing}

Point data were processed in SDCimport software for initial filtering and multiple-timearound (MTA) disambiguation. MTA errors, corrected in this process, are the result of imprecise interpretations of received pulse time intervals and occur more frequently with higher pulse refresh rates. IMU and GPS data were used to integrate flightline information with the point cloud in Spatial Explorer software. The point data were calibrated at an incrementally precise scale of sensor movement and behavior, incorporating sensor velocity, roll, pitch, and yaw fluctuations throughout the survey (fig. 2). 
Points were classified in accordance with American Society for Photogrammetry and Remote Sensing (ASPRS) 2014 guidelines, using macros designed in Terrasolid software. Careful attention was given to the interpolation of the project's ground surface to compensate for inconsistent penetration through low vegetation as a function of the scan angle. Once classified, points underwent a geometric transformation and were converted from ellipsoidal heights to GEOID12B (Alaska) heights.

Raster products were derived from the point cloud using ArcMap. The DTM was interpolated from all ground class returns using a tin-based method. The DSM was likewise interpolated from only the first returns for all classes. An intensity image was produced in ArcMap, using closest-to-mean binning.

\section{Classified Point Cloud}

Classified point cloud data is provided in this collection in compressed LAZ format. Data are classified in accordance with ASPRS 2014 guidelines and contain return and intensity information. The average pulse spacing was $10.67 \mathrm{~cm}$ and the average density was $87.75 \mathrm{pts} / \mathrm{m}^{2}$ (fig. 2). Elevation surfaces interpolated from areas with a point density of fewer than $4 \mathrm{pts} / \mathrm{m}^{2}$ were classified as no data.

\section{Digital Surface Model}

The DSM represents surface elevations, including heights of vegetation, buildings, bridges, etc. The DSM is a single band, 32-bit GeoTIFF file, with a ground sample distance of 1 meter. No Data value is set to $-3.40282306074 \mathrm{e}+038$.

\section{Digital Terrain Model}

The DTM represents surface elevations of ground surfaces, excluding vegetation, bridges, buildings, etc. The DTM is a single-band, 32-bit float GeoTIFF file, with a ground sample distance of 1 meter. No Data value is set to $-3.40282306074 \mathrm{e}+038$.

\section{Lidar Intensity Image}

The lidar intensity image describes the relative amplitude of reflected signals contributing to the point cloud. Lidar intensity is largely a function of scanned object reflectance in relation to the signal frequency, is dependent on ambient conditions, and is not necessarily consistent between separate scans. The intensity image is a single-band, 32-bit float GeoTIFF file with a ground sample distance of 1 meter. No Data value is set to -3.40282306074e+038 (32-bit, floatingpoint minimum). 


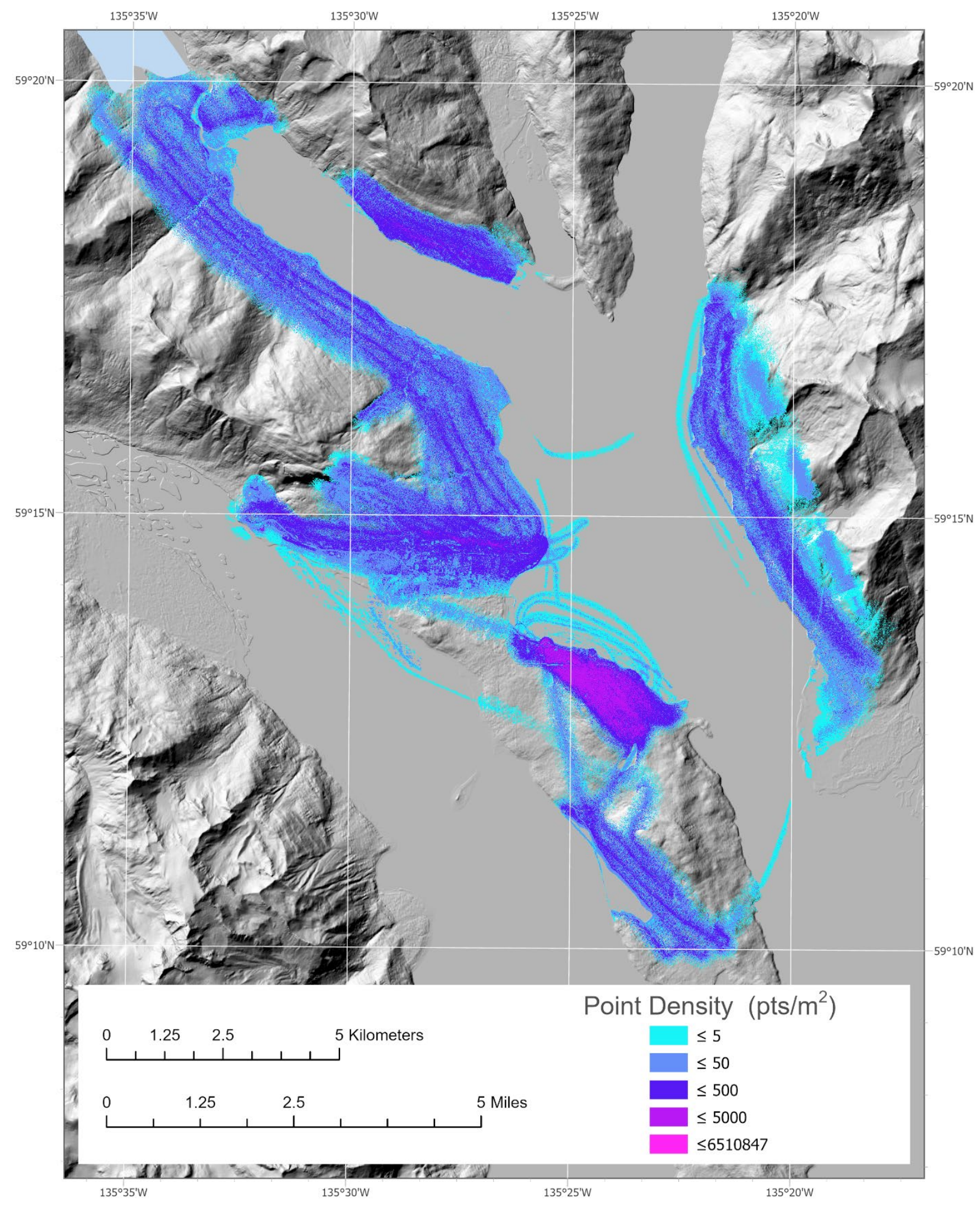

Figure 2. Ground point density for the survey displayed as a 1-meter raster. 


\section{SURVEY REPORT}

\section{Ground Survey Details}

The DMLW collected 67 points using a Trimble R10 GNSS instrument. Of these points, 31 were used as control points, while 36 were used as checkpoints.

\section{Coordinate system and Datum}

All data were processed and delivered in NAD83 UTM8N and vertical datum NAVD88 GEOID12B.

\section{Horizontal Accuracy}

Horizontal accuracy was not measured for this collection.

\section{Vertical Accuracy}

A mean offset of $32.3 \mathrm{~cm}$ was measured between 31 control points and the point cloud. This offset was reduced to 0 by performing a vertical transformation of the lidar point data. Thirtysix checkpoints were used to determine the vertical accuracy of the point cloud ground class, using a tin-based approach. The final accuracy was calculated to have a root mean square error (RMSE) of $34.8 \mathrm{~cm}$.

\section{Data Consistency and Completeness}

This data release is complete, and there is no over collect, except for the aircraft turns that were eliminated from the dataset. The data quality is consistent throughout the survey.

\section{ACKNOWLEDGMENTS}

These data were paid for by the State of Alaska and collected and processed by DGGS.

\section{APPENDIX: CONTROL POINTS}

\begin{tabular}{|c|c|c|c|c|c|}
\hline Number & Easting & Northing & Known Z & Laser Z & Dz \\
\hline $\mathbf{1}$ & 477820.2 & 6559602 & 7.247 & 7.75 & 0.503 \\
\hline $\mathbf{2}$ & 469445.8 & 6576359 & 6.577 & 6.46 & -0.117 \\
\hline $\mathbf{3}$ & 469423.9 & 6576377 & 7.898 & 7.71 & -0.188 \\
\hline $\mathbf{4}$ & 469358.5 & 6576403 & 7.549 & 7.36 & -0.189 \\
\hline $\mathbf{5}$ & 469276.9 & 6576373 & 7.441 & 7.24 & -0.201 \\
\hline $\mathbf{6}$ & 468433.4 & 6575419 & 7.457 & 7.32 & -0.137 \\
\hline $\mathbf{7}$ & 468491.5 & 6575373 & 7.492 & 7.35 & -0.142 \\
\hline $\mathbf{8}$ & 468532.3 & 6575360 & 7.469 & 7.31 & -0.159 \\
\hline $\mathbf{9}$ & 468563.1 & 6575353 & 7.417 & 7.29 & -0.127 \\
\hline $\mathbf{1 0}$ & 477824.9 & 6559611 & 7.107 & 7.91 & 0.803 \\
\hline $\mathbf{1 1}$ & 477871.5 & 6559579 & 7.495 & 8.34 & 0.845 \\
\hline $\mathbf{1 2}$ & 477922.8 & 6559534 & 8.363 & 9.18 & 0.817 \\
\hline
\end{tabular}




\begin{tabular}{|c|c|c|c|c|c|}
\hline Number & Easting & Northing & Known Z & Laser Z & Dz \\
\hline 13 & 477979.8 & 6559487 & 8.691 & 9.47 & 0.779 \\
\hline 14 & 477990.5 & 6559478 & 8.63 & 9.37 & 0.74 \\
\hline 15 & 475186.4 & 6567682 & 129.898 & 130.13 & 0.232 \\
\hline 16 & 475171.8 & 6567702 & 132.519 & 132.78 & 0.261 \\
\hline 17 & 475147.5 & 6567758 & 139.992 & 140.48 & 0.488 \\
\hline 18 & 475223.4 & 6567626 & 122.044 & 122.33 & 0.286 \\
\hline 19 & 475255.9 & 6567621 & 118.923 & 119.19 & 0.267 \\
\hline 20 & 475260.9 & 6567590 & 113.682 & 113.94 & 0.258 \\
\hline 21 & 475257.2 & 6567583 & 112.502 & 112.77 & 0.268 \\
\hline 22 & 476292.8 & 6565075 & 17.19 & 17.46 & 0.27 \\
\hline 23 & 476300 & 6565068 & 18.37 & 18.64 & 0.27 \\
\hline 24 & 476317.5 & 6565052 & 21.439 & 21.7 & 0.261 \\
\hline 25 & 476335.3 & 6565037 & 24.028 & 24.23 & 0.202 \\
\hline 26 & 473098.2 & 6567361 & 72.712 & 72.78 & 0.068 \\
\hline 27 & 473037.5 & 6567362 & 70.305 & 69.76 & -0.545 \\
\hline 28 & 472999.6 & 6567360 & 68.947 & 69.08 & 0.133 \\
\hline 29 & 472972.3 & 6567360 & 67.588 & 67.68 & 0.092 \\
\hline 30 & 472959 & 6567360 & 66.978 & 67.07 & 0.092 \\
\hline 31 & 476105.5 & 6564810 & 113.068 & 112.81 & -0.258 \\
\hline Average $\mathrm{dz}(\mathrm{m})$ & 0.19 & & & & \\
\hline Minimum dz (m) & -0.545 & & & & \\
\hline Maximum dz (m) & 0.845 & & & & \\
\hline Average & 0.323 & & & & \\
\hline RMSE dz (m) & 0.4 & & & & \\
\hline Std dev dz (m) & 0.358 & & & & \\
\hline
\end{tabular}




\section{APPENDIX: CHECKPOINTS}

\begin{tabular}{|c|c|c|c|c|c|}
\hline Number & Easting & Northing & Known Z & Laser Z & Dz \\
\hline 1 & 469399.1 & 6576389 & 7.768 & 7.42 & -0.348 \\
\hline 2 & 469332.3 & 6576397 & 7.5 & 7.1 & -0.4 \\
\hline 3 & 469316.6 & 6576391 & 7.31 & 6.92 & -0.39 \\
\hline 4 & 469308.8 & 6576387 & 7.26 & 6.87 & -0.39 \\
\hline 5 & 469301.2 & 6576384 & 7.26 & 6.87 & -0.39 \\
\hline 6 & 468427.9 & 6575443 & 6.288 & 6.03 & -0.258 \\
\hline 7 & 468452.5 & 6575398 & 7.505 & 7.15 & -0.355 \\
\hline 8 & 468460 & 6575392 & 7.514 & 7.14 & -0.374 \\
\hline 9 & 468474.3 & 6575381 & 7.483 & 7.15 & -0.333 \\
\hline 10 & 468502.8 & 6575368 & 7.511 & 7.16 & -0.351 \\
\hline 11 & 468542.9 & 6575358 & 7.408 & 7.06 & -0.348 \\
\hline 12 & 477953.3 & 6559508 & 8.592 & 9.15 & 0.558 \\
\hline 13 & 477970.9 & 6559494 & 8.671 & 9.22 & 0.549 \\
\hline 14 & 477993.8 & 6559468 & 6.47 & 7.09 & 0.62 \\
\hline 15 & 477988.8 & 6559472 & 6.44 & 7.21 & 0.77 \\
\hline 16 & 475209.3 & 6567629 & 123.475 & 123.53 & 0.055 \\
\hline 17 & 475207.9 & 6567638 & 124.535 & 124.58 & 0.045 \\
\hline 18 & 475165.3 & 6567712 & 133.76 & 133.82 & 0.06 \\
\hline 19 & 475155.1 & 6567735 & 136.551 & 136.61 & 0.059 \\
\hline 20 & 475261 & 6567614 & 117.602 & 117.7 & 0.098 \\
\hline 21 & 475263.2 & 6567605 & 116.232 & 116.22 & -0.012 \\
\hline 22 & 475262.6 & 6567598 & 114.962 & 114.93 & -0.032 \\
\hline 23 & 475239 & 6567638 & 122.254 & slope & $*$ \\
\hline 24 & 476327 & 6565044 & 22.958 & 22.96 & 0.002 \\
\hline 25 & 476343 & 6565032 & 24.687 & 24.68 & -0.007 \\
\hline 26 & 473193.6 & 6567374 & 74.578 & 74.06 & -0.518 \\
\hline 27 & 473071.6 & 6567362 & 71.433 & slope & $*$ \\
\hline 28 & 472985.4 & 6567360 & 68.197 & 68.12 & -0.077 \\
\hline 29 & 472942.1 & 6567360 & 66.489 & 66.44 & -0.049 \\
\hline 30 & 476230.2 & 6564807 & 101.632 & 101.51 & -0.122 \\
\hline 31 & 476194.6 & 6564809 & 103.724 & 103.41 & -0.314 \\
\hline 32 & 476155.6 & 6564810 & 107.806 & 107.6 & -0.206 \\
\hline 33 & 476146.1 & 6564810 & 108.826 & 108.52 & -0.306 \\
\hline 34 & 476117 & 6564810 & 111.887 & 111.59 & -0.297 \\
\hline 35 & 476095.6 & 6564810 & 114.118 & 113.64 & -0.478 \\
\hline 36 & 476076 & 6564810 & 116.109 & 115.58 & -0.529 \\
\hline 37 & 476048.5 & 6564810 & 118.07 & 117.63 & -0.44 \\
\hline
\end{tabular}




\begin{tabular}{|c|c|c|c|c|c|}
\hline Number & Easting & Northing & Known Z & Laser Z & Dz \\
\hline $\mathbf{3 8}$ & 476056.8 & 6564814 & 117.79 & 117.7 & -0.09 \\
\hline Average dz (m) & -0.128 & & & \\
\hline Minimum dz (m) & -0.529 & & & \\
\hline Maximum dz (m) & 0.77 & & & \\
\hline Average & 0.284 & & & \\
\hline RMSE dz (m) & 0.348 & & & \\
\hline Std dev dz (m) & 0.328 & & & \\
\hline
\end{tabular}

